\section{Recurrence and additional treatment of cystic thyroid nodules after ethanol ablation: validation of three proposed criteria}

\author{
Younghee Yim ${ }^{1,2}$, Jung Hwan Baek ${ }^{2}$, Sae Rom Chung ${ }^{2}$, Young Jun Choi ${ }^{2}$, Jeong Hyun Lee ${ }^{2}$ \\ 'Department of Radiology, Chung-Ang University Hospital, Chung-Ang University College \\ of Medicine, Seoul; ${ }^{2}$ Department of Radiology and Research Institute of Radiology, Asan \\ Medical Center, University of Ulsan College of Medicine, Seoul, Korea
}

Purpose: We evaluated the use of three criteria to determine the need for additional treatment of cystic thyroid nodules after their recurrence following ethanol ablation (EA).

Methods: In total, 154 patients (male:female=30:124; mean age, 53.4 years; range, 23 to 79 years) with 154 thyroid nodules (49 cystic and 105 predominantly cystic nodules) who presented between January 2014 and August 2017 were enrolled. All patients underwent follow-up ultrasonography (US) 1 month after EA, and were divided into therapeutic success and failure groups. Therapeutic success was defined as the absence of any residual fluid or sufficient volume reduction $(\geq 50 \%)$ with improvement of nodule-related symptoms. The therapeutic failure was defined according to three previously suggested criteria for recommending additional treatment: nodules with $\geq 1 \mathrm{~mL}$ of remnant fluid (criterion 1), volume reduction $<50 \%$ (criterion 2 ), and demonstration of a solid component with vascularity (criterion 3).

Results: Thyroid nodules treated by EA showed significant volume reduction $(18.4 \pm 21.6 \mathrm{~mL}$ to $4.2 \pm 6.5 \mathrm{~mL}$ [1-month follow-up] to $1.9 \pm 3.3 \mathrm{~mL}$ [final follow-up], $\mathrm{P}<0.001$ ) and improvement in clinical problems. Therapeutic failure were 26 patients according to criteria 1, 14 patients according to criteria 2, and 35 patients according to criteria 3 . Additional treatment was unnecessary in $81.3 \%, 70.0 \%$, and $77.8 \%$ of patients deemed to need it according to criteria 1,2 , and 3 , respectively.

Conclusion: The choice to perform additional treatment after EA should be made according to a combination of clinical problems and US features. Understanding this concept will be useful in planning further treatment following US-guided EA.

Keywords: Thyroid nodules; Ethanol; Ablation; Recurrence

\section{Introduction}

Imaging-guided non-surgical procedures such as ethanol ablation (EA) have been proposed as effective and less invasive approaches for the management of cystic (pure cystic) or predominantly

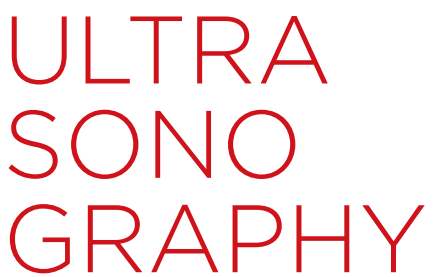

\section{ORIGINAL ARTICLE}

https://doi.org/10.14366/usg.20039 pISSN: 2288-5919 elSSN: 2288-5943 Ultrasonography 2021;40:378-386

Received: March 17, 2020

Revised: November 1, 2020

Accepted: November 3, 2020

Correspondence to: Jung Hwan Baek, MD, PhD, Department of Radiology and Research Institute of Radiology, Asan Medical Center, University of Ulsan College of Medicine, 88 Olympic-ro 43-gil, Songpa-gu, Seoul 05505, Korea

Tel. +82-2-3010-4348

Fax. +82-2-476-0090

E-mail: radbaek@naver.com

This is an Open Access article distributed under the terms of the Creative Commons Attribution NonCommercial License (http://creativecommons.org/ licenses/by-nc/4.0/) which permits unrestricted noncommercial use distribution and reproduction in any medium, provided the original work is properly cited.

Copyright (C) 2021 Korean Society of Ultrasound in Medicine (KSUM)

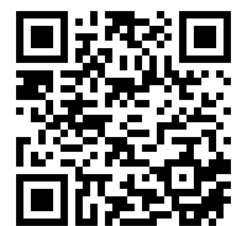

How to cite this article:

Yim Y, Baek JH, Chung SR, Choi YJ, Lee JH. Recurrence and additional treatment of cystic thyroid nodules after ethanol ablation: validation of three proposed criteria. Ultrasonography. 2021 Jul;40(3):378-386. 
cystic (cystic component $>50 \%$ ) thyroid nodules causing pressure symptoms or complaints of neck bulging [1,2]. The Korean Society of Thyroid Radiology (KSThR) strongly recommended EA as the firstline treatment method for cystic and predominantly cystic nodules that are not treated with simple aspiration [3].

Previous studies showed that EA achieved volume reduction for cystic nodules ( $85 \%-95 \%$ of cases) and predominantly cystic nodules (60\%-90\% of cases) [4]; however, even though EA is known to be effective for reducing the volume of cystic or predominantly cystic thyroid nodules in most cases, nodules sometimes recur, and additional treatment needs to be considered [5-8]. For example, the KSThR suggested radiofrequency ablation (RFA) for incompletely resolved symptoms or recurrence following EA [3]. Although the additional treatment of recurrent cystic or predominantly cystic thyroid nodules is effective, different criteria have been suggested for defining recurrence and the need for additional treatment, and the decision can be challenging to make in daily practice $[6,7,9]$. According to previous studies, recurrence is usually identified at 1-month follow-up ultrasonography (US) after $E A$, and three different definitions of recurrence have been suggested, as follows: (1) nodules containing $\geq 1 \mathrm{~mL}$ of cystic fluid [6], (2) a volume reduction ratio of $<50 \%[7,9]$, and (3) a vascular solid component in treated nodules [2].

Thus, a reasonable definition of recurrence requiring further treatment is important for an effective additional treatment strategy. We therefore evaluated the above mentioned three previously suggested US-based criteria for defining recurrence requiring treatment after EA of cystic or predominantly cystic thyroid nodules.

\section{Materials and Methods}

Our institutional review board approved this retrospective study (s2017-2329-0004), and the requirement for informed consent was waived. Informed consent for US-guided procedures was obtained from all patients prior to each procedure.

\section{Patients}

A total of 253 consecutive patients who underwent EA for cystic neck lesions at our institution between January 2014 and August 2017 were enrolled in this study Fig.1. The eligibility criteria were as follows: (1) cystic (pure cystic) or predominantly cystic (cystic component $>50 \%$ ) thyroid nodules; (2) pressure symptoms and/ or cosmetic problems; (3) normal serum concentrations of thyroid hormones and thyrotropin; (4) benign cytological results; and (5) no suspicious malignant features on US examination such as microcalcification, nonparallel orientation, or a spiculated or microlobulated margin [10].

Ninety-nine patients were excluded: 32 because they were lost to follow-up and 67 because they were treated for non-thyroidal lesions, such as thyroglossal duct cyst or lymphatic malformation. Finally, 154 patients (male:female=30:124; mean age \pm standard deviation, 53.4 \pm 12.8 years; range, 23 to 79 years) with 154 cystic or predominantly cystic thyroid nodules were analyzed. We performed US-guided fine-needle aspiration (FNA) for all enrolled nodules (average, 1.5 times; range, 1 to 5 times) and obtained results of non-diagnostic $(n=46,29.9 \%)$ or benign ( $n=108,70.1 \%)$. After reviewing the US images and considering the biopsy numbers, we assumed that the non-diagnostic results were benign since the

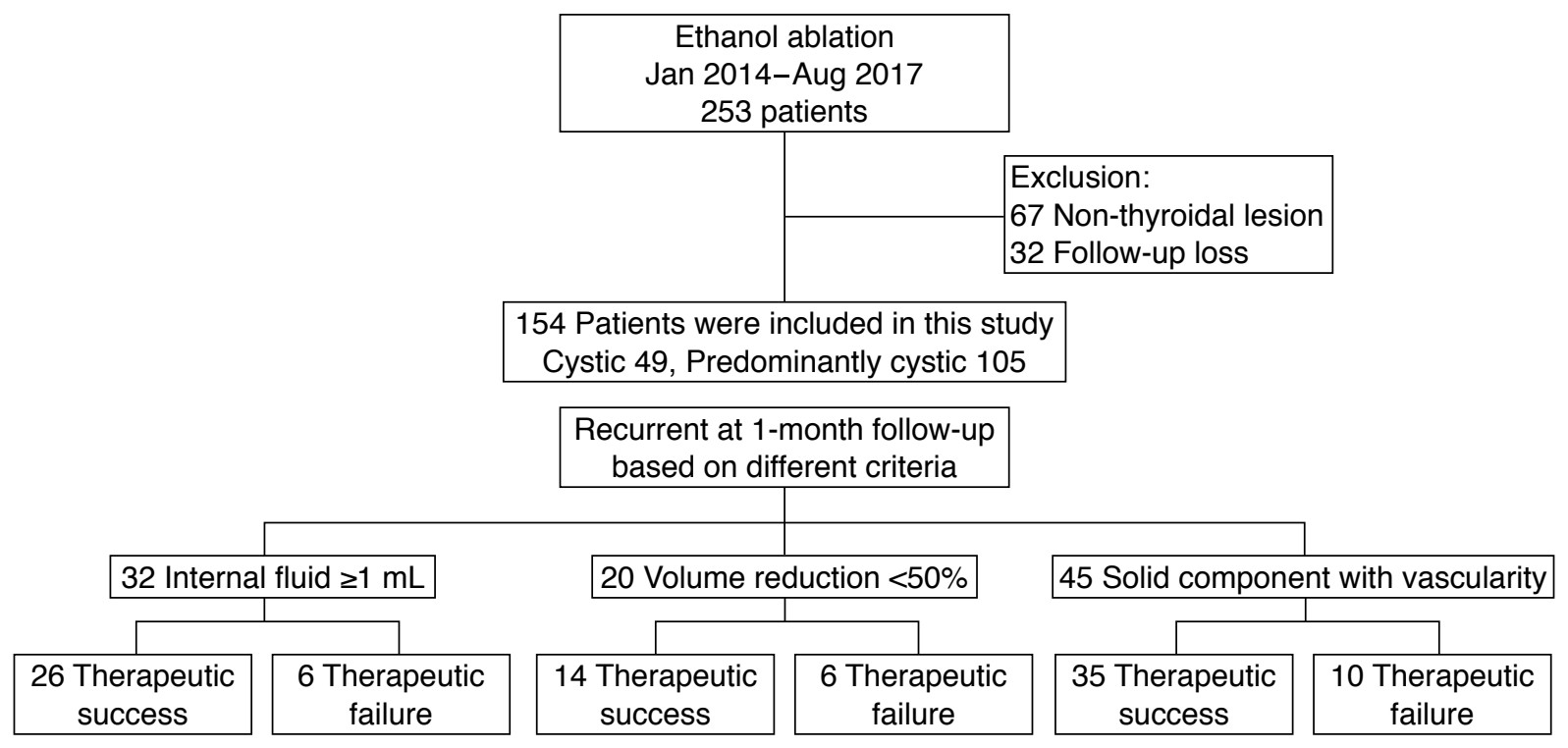

Fig. 1. Study population diagram. 
non-diagnostic FNA results were due to pure cysts without a solid component. All 154 patients underwent follow-up US at 1 month after EA, and they were divided into two groups according to the final results: therapeutic success according to US (volume reduction $\geq 50 \%$ ) and therapeutic failure according to US (volume reduction $<50 \%$ or a requirement for additional treatment).

\section{Pre-ablation Assessment}

Before patients underwent $E A$, two experienced radiologists assessed the findings of US-guided FNA, laboratory examinations, and symptoms. The characteristics of each thyroid nodule, including its size, solid component, and vascularity, were evaluated using an iU22 (Philips Healthcare, Bothell, WA, USA) or EUB-7500 US unit (Hitachi Medical Systems, Tokyo, Japan) with a linear high-frequency probe $(5-14 \mathrm{MHz})$. The three orthogonal diameters of each nodule were measured on US, and the nodule volume (V) was calculated using the equation $V=\pi a b c / 6$, where $a$ is the largest diameter, and $b$ and $c$ are the two perpendicular diameters [11].

Nodule vascularity was graded as follows: grade 1, no vascularity; grade 2, peripheral vascularity only; grade 3, intranodular vascularity $\leq 50 \%$; and grade 4 , intranodular vascularity $>50 \%[12,13]$.

The symptom score was calculated using a $10-\mathrm{cm}$ visual analogue scale (range, 0 to 10). The cosmetic score was assessed as grade 1 (no palpable mass), grade 2 (no cosmetic problem, but a palpable nodule), grade 3 (a cosmetic problem on swallowing only), or grade 4 (a readily detectable cosmetic problem) $[14,15]$.

\section{Ethanol Ablation}

EA was conducted on an outpatient basis by two radiologists with $>10$ years of experience, as described in previous articles $[12,16,17]$. First, a 16-G or 18-G needle was inserted into the cystic area of the nodule under guidance from a transverse US view. The cystic component was maximally removed when the needle tip approached the center of the cyst, and internal debridement was irrigated with saline. A volume of $99 \%$ ethanol corresponding to about $50 \%$ of that of the aspirated fluid volume was then injected slowly into the cyst. The injected ethanol (average, $8.3 \mathrm{~mL}$; range, 1 to $20 \mathrm{~mL}$ based on the aspirated fluid amount) and needle were removed around 2 minutes later. After the procedure, the patient stayed at the hospital for about 30 minutes and was then discharged unless an immediate adverse event was noted. Repeat EA was performed using the same procedure as the initial EA.

\section{Follow-up}

Follow-up US examinations were performed on the treated nodules at 1, 6, and 12 months, and then every 6-12 months thereafter [12]. Changes in the cystic portion, vascularity, diameter, and volume were evaluated. The effect of the treatment was assessed by measuring the volume reduction ratio, and by assessing the improvement in symptoms and cosmetic problems. Therapeutic success was defined as a volume reduction $>50 \%$ at the last follow-up [18]. If a further US examination result after the 1-month follow-up was unavailable for any reason (such as follow-up at another hospital or refusal to attend follow-up because of absence of symptoms), the patient's status was checked with a telephone interview, and the procedure was considered as a therapeutic success if the first follow-up at 1 month after EA showed a volume reduction ratio of $>50 \%$. Any adverse events during the follow-up period were also checked.

The volume reduction ratio (VRR) was defined as follows [19]:

$$
V R R(\%)=\frac{\text { Initial volume }- \text { Post treatment volume }}{\text { Initial volume }} \times 100
$$

Recurrent thyroid nodules were defined according to three previously suggested criteria (Fig. 1): (1) nodules with a fluid component $\geq 1 \mathrm{~mL}[6]$, (2) shrinkage of $\leq 50 \%$ of the initial nodule volume $[7,9]$, and (3) demonstration of a solid component with vascularity [2]. The final results were compared for recurrence defined according to each of those three definitions. Delayed recurrence was defined as no recurrence detected on US at 1-month post-EA, but the observation of a newly developed cystic portion of the treated thyroid nodule during the later follow-up period [2].

Additional treatment was not performed in all nodules defined as showing clinical therapeutic failure at the 1-month follow-up US examination, as a conservative treatment strategy was used in some cases. We decided upon additional EA after a 2-month follow-up examination to avoid additional EA if possible. Avoidable additional EA was defined as occurring in patients for whom therapeutic success was achieved at the last follow-up without additional treatment.

When a patient requested additional treatment because of incompletely resolved nodule-related symptoms and/or cosmetic problems, additional treatment was performed. These cases were regarded as clinical therapeutic failure.

\section{Statistical Analysis}

Statistical analyses were performed using SPSS for Windows version 18.0 (SPSS, Chicago, IL, USA) and R version 3.4.2 (R Foundation for Statistical Computing, Vienna, Austria). To evaluate the efficacy of $E A$, the paired $t$ test was test was used to compare variables (changes in the largest diameter, volume, vascularity, and symptomatic and cosmetic scores) between the pre-EA, 1-month follow-up, and the last follow-up examinations.

To evaluate the previously proposed criteria for recurrence after EA, the patients' final results were classified as therapeutic success 
or failure, and the US results were compared using the $t$ test. The level of significance was defined as $\mathrm{P}<0.05$.

\section{Results}

In total, $135(87.7 \%)$ patients achieved therapeutic success and 19 patients (12.3\%) experienced therapeutic failure. Table 1 shows the pre-treatment characteristics and changes in parameters during follow-up. At the 1-month and last follow-up, the volumes of the treated nodules had decreased significantly $(P<0.001)$, and the clinical problems of the patients had improved significantly $(\mathrm{P}<0.001)$.

When the three previously proposed criteria for defining recurrence requiring further treatment $[2,6,7,9]$ were applied to our patient group, 32 patients would have required further treatment according to criterion 1 (nodules with a fluid component $\geq 1 \mathrm{~mL}$ ), 20 patients according to criterion 2 (shrinkage of $<50 \%$ ), and 45 patients according to criterion 3 (a solid component with vascularity). For these three groups, the proportion of cases of avoidable additional EA was $81.3 \%$ (26 of 32 ), $70.0 \%$ (14 of 20 ), and $77.8 \%$ (35 of 45 ), respectively, with significantly higher numbers of patients achieving therapeutic success than showing therapeutic failure (therapeutic failure: $18.7 \%$ [6 of 32], $P<0.001$; $30.0 \%$ [6 of 20], $P=0.013$; and $22.2 \%$ [10 of 45 ], $P<0.001$, respectively) (Table 2, Figs. 2-4).

A characteristic finding was that almost half of the cases of therapeutic failure showed increased vascularity of grade 3 or 4 (47.4\%, 9 of 19). Seven patients showed delayed recurrence, four of whom underwent additional treatment with RFA and finally achieved therapeutic success, defined as a volume reduction of $>50 \%$ at 12 months after treatment [20]; their average volume reduction ratio was $80.2 \%$. The other two patients who did not undergo additional treatment showed final therapeutic success (VRR of $76.3 \%$ and $51.7 \%$ at 13 - and 12 -month follow-up examinations, respectively), and one patient was clinically asymptomatic (VRR, $28.2 \%)$.

The mean follow-up period was $18.1 \pm 13.4$ months. The final follow-up of six patients (3.9\%) was at 1 month, while the others underwent their final follow-up examinations at 6 months or more ( 6 months, 48 patients [31.2\%]; 12 months, 31 patients [20.1\%]; more than 12 months, 69 patients [44.8\%]). The follow-up period did not show a statistically significant difference between the therapeutic success and failure groups (18.4 \pm 13.4 months; range, 1 to 47 months vs. $16.1 \pm 13.0$ months; range, 1 to 46 months; $P=0.483$ ).

Table 2. Comparison the therapeutic success and failure groups for patients who would be considered for additional treatment

\begin{tabular}{|c|c|c|c|}
\hline $\begin{array}{l}\text { Proposed criteria for } \\
\text { additional treatment }\end{array}$ & $\begin{array}{c}\text { Therapeutic } \\
\text { success }(n=135)\end{array}$ & $\begin{array}{c}\text { Therapeutic } \\
\text { failure }(n=19)\end{array}$ & P-value ${ }^{a}$ \\
\hline \multicolumn{4}{|l|}{$\begin{array}{l}\text { Residual fluid }>1 \mathrm{~mL} \\
(\mathrm{n}=32,20.8 \%)\end{array}$} \\
\hline No. & $26(81.3)$ & $6(18.7)$ & $<0.001$ \\
\hline Volume $(\mathrm{mL})$ & $2.9 \pm 0.8$ & $9.5 \pm 12.6$ & 0.009 \\
\hline Vascularity & $10(38.5)$ & $6(100)$ & 0.008 \\
\hline \multicolumn{4}{|l|}{$\begin{array}{l}\text { Volume reduction }<50 \% \\
(\mathrm{n}=20,13.0 \%)\end{array}$} \\
\hline No. & $14(70.0)$ & $6(30.0)$ & 0.013 \\
\hline Volume (mL) & $7.6 \pm 7.2$ & $18.8 \pm 16.2$ & 0.042 \\
\hline Vascularity & $6(42.9)$ & $6(100)$ & 0.020 \\
\hline \multicolumn{4}{|l|}{$\begin{array}{l}\text { Solid component with } \\
\text { vascularity }(n=45,29.2 \%)\end{array}$} \\
\hline No. ${ }^{b)}$ & $35(77.8)$ & $10(22.2)$ & $<0.001$ \\
\hline Volume (mL) & $3.2 \pm 5.2$ & $3.9 \pm 2.3$ & 0.683 \\
\hline Vascularity & $35(100)$ & $10(100)$ & - \\
\hline
\end{tabular}

Values reported as number (\%) or mean \pm standard deviation.

Therapeutic success was defined as a volume reduction $\geq 50 \%$, and therapeutic failure was defined as a volume reduction $<50 \%$ or the undertaking of additional treatment because of incompletely resolved clinical problems.

${ }^{a}$ The paired t test was used to compare the variables between the therapeutic success and therapeutic failure groups. ${ }^{\text {b) }}$ Number of patients based on each criterion.

Table 1. Efficacy of EA over the follow-up period

\begin{tabular}{|c|c|c|c|c|c|}
\hline Parameter $(n=154)$ & Before EA & 1-Month follow-up & P-value ${ }^{a)}$ & Final follow-up & P-value \\
\hline Largest diameter (cm) & $3.9 \pm 1.4$ & $2.3 \pm 4.2$ & $<0.001$ & $1.5 \pm 1.0$ & $<0.001$ \\
\hline Nodule volume (mL) & $18.4 \pm 21.6$ & $4.2 \pm 6.5$ & $<0.001$ & $1.9 \pm 3.3$ & $<0.001$ \\
\hline Vascularity grade & $0.5 \pm 0.8$ & $0.7 \pm 0.9$ & 0.053 & $0.6 \pm 0.9$ & 0.180 \\
\hline Volume reduction ratio & & $76.1 \pm 20.8$ & & $87.4 \pm 18.4$ & $<0.001$ \\
\hline Symptom score & $2.6 \pm 2.0$ & $0.7 \pm 0.9$ & $<0.001$ & $0.3 \pm 0.7$ & $<0.001$ \\
\hline Cosmetic score & $3.9 \pm 0.6$ & $2.3 \pm 0.9$ & $<0.001$ & $1.6 \pm 0.9$ & $<0.001$ \\
\hline
\end{tabular}

Values reported as mean \pm standard deviation.

EA, ethanol ablation.

${ }^{a}$ The paired $t$ test was used to compare the variables between the initial assessment and 1 -month follow-up. ${ }^{b}$ The paired $t$ test was used to compare the variables between the 1 -month and final follow-up. 


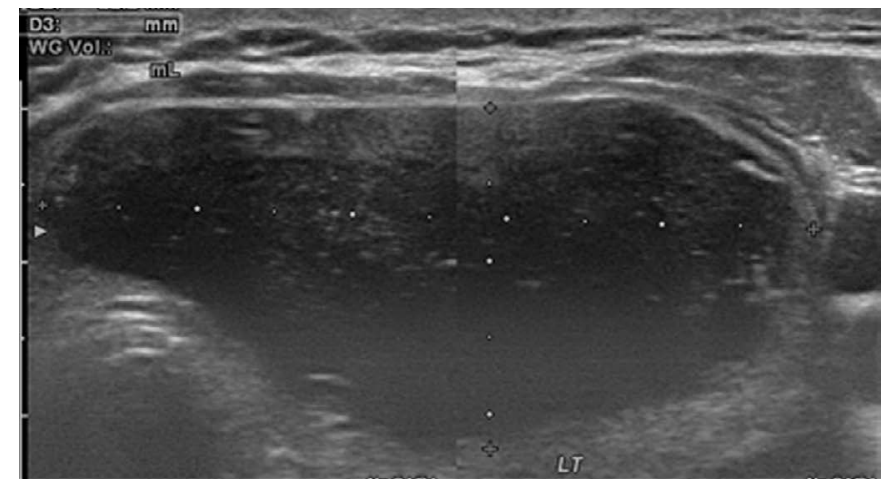

A

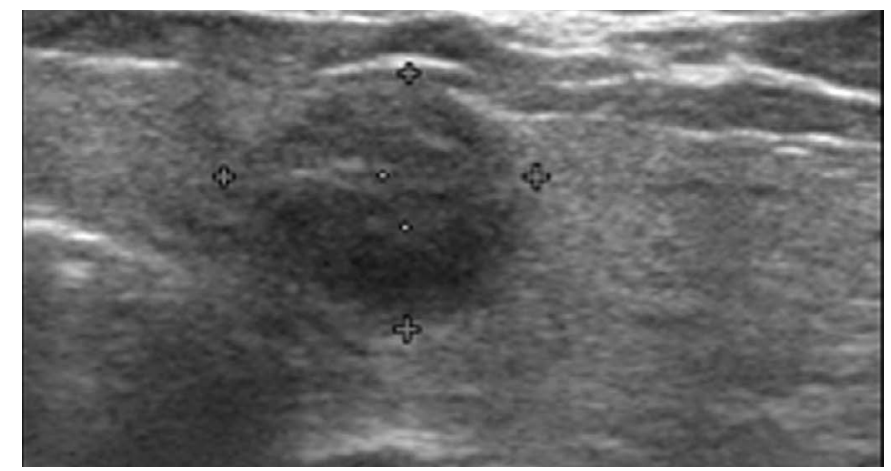

C

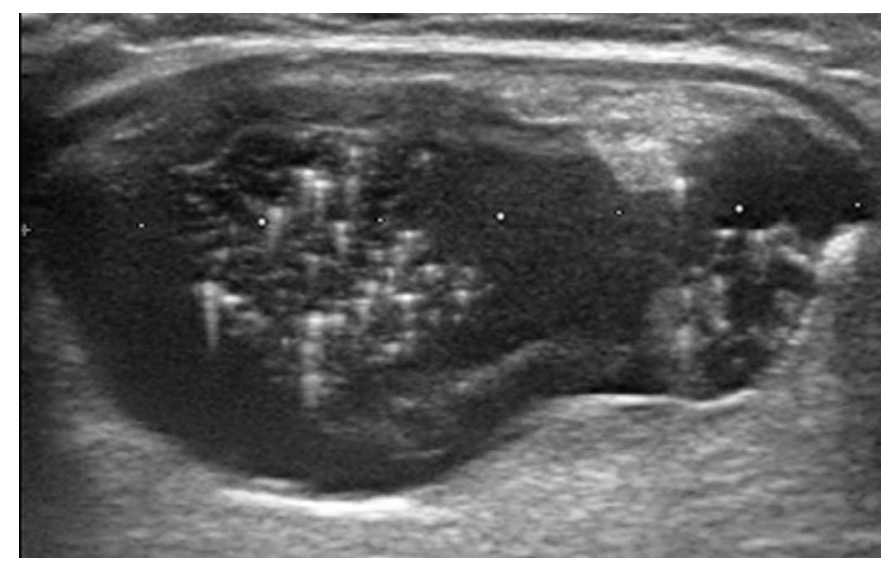

A

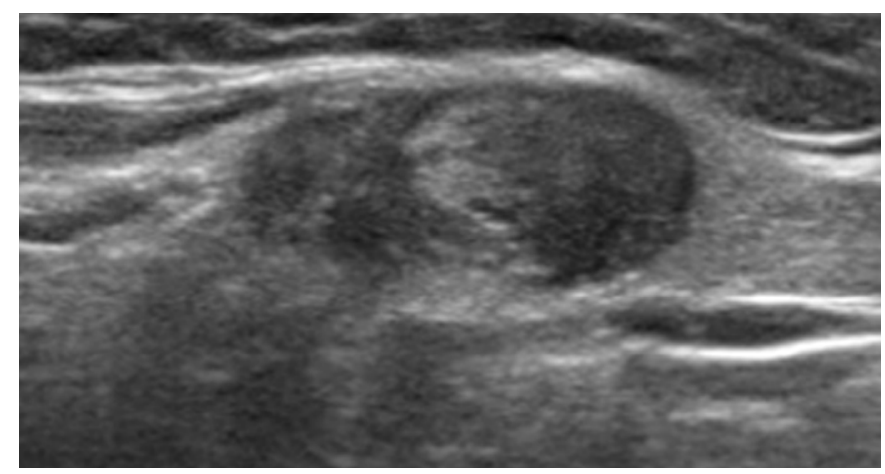

C

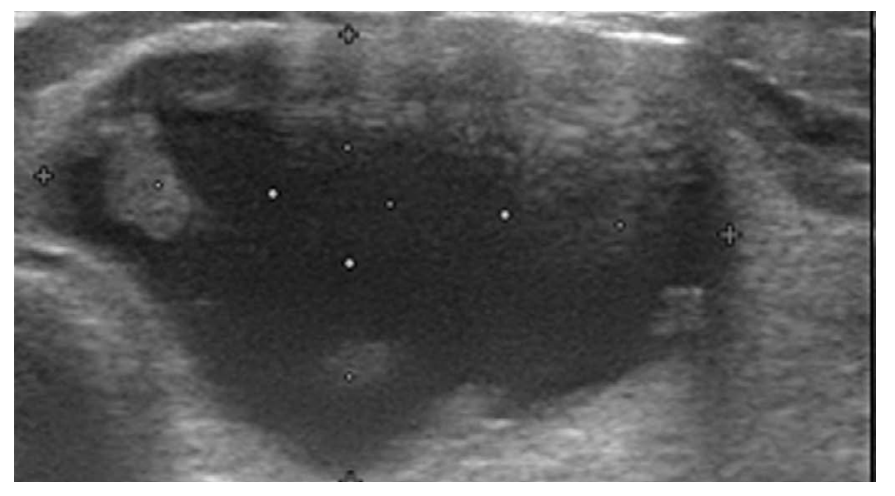

B

Fig. 2. A 64-year-old woman with thyroid cyst.

A. At the initial work-up, a predominantly cystic nodule was found, with benign cytology on fine-needle aspiration in the left thyroid gland with a volume of $28 \mathrm{~mL}$. The initial cosmetic score and symptom score were both 4 . The patient underwent ethanol ablation with $10 \mathrm{~mL}$ of ethanol followed by the aspiration of $25 \mathrm{~mL}$ of cystic contents. B. At a 1-month follow-up, the residual cystic volume was about $9 \mathrm{~mL}$, but the symptoms had disappeared. C. The patient underwent regular follow-up rather than additional treatment, and the nodule had collapsed on 24-month follow-up ultrasonography (volume, $0.5 \mathrm{~mL}$; volume reduction ratio, 98.2\%).

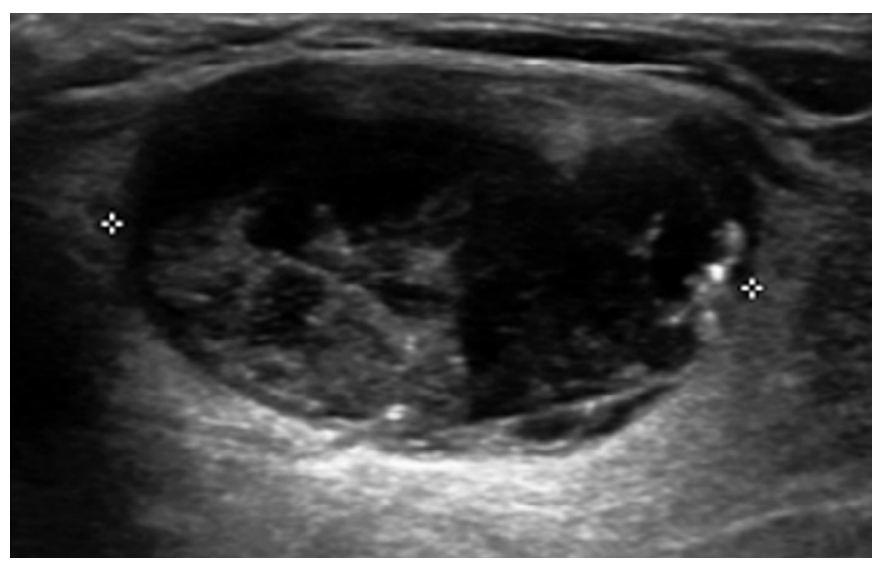

B

Fig. 3. A 71-year-old woman with predominantly cystic thyroid nodule. A. At the initial work-up, there was a predominantly cystic mass of about $10.8 \mathrm{~mL}$ with benign cytology on fine-needle aspiration in the left thyroid lobe. The initial cosmetic score was 4 , and the symptom score was 2. The patient underwent ethanol ablation with $5 \mathrm{~mL}$ of ethanol followed by the aspiration of $10 \mathrm{~mL}$ of cystic contents. B. At a 1-month follow-up, the residual cystic volume was $7.4 \mathrm{~mL}$, which was a $<50 \%$ volume reduction. As she did not have any symptoms, the patient did not want to undergo additional treatment. C. She underwent regular follow-up without additional treatment, and the nodule had collapsed on 36-month follow-up ultrasonography (volume, $0.7 \mathrm{~mL}$; volume reduction ratio, 93.5\%). 


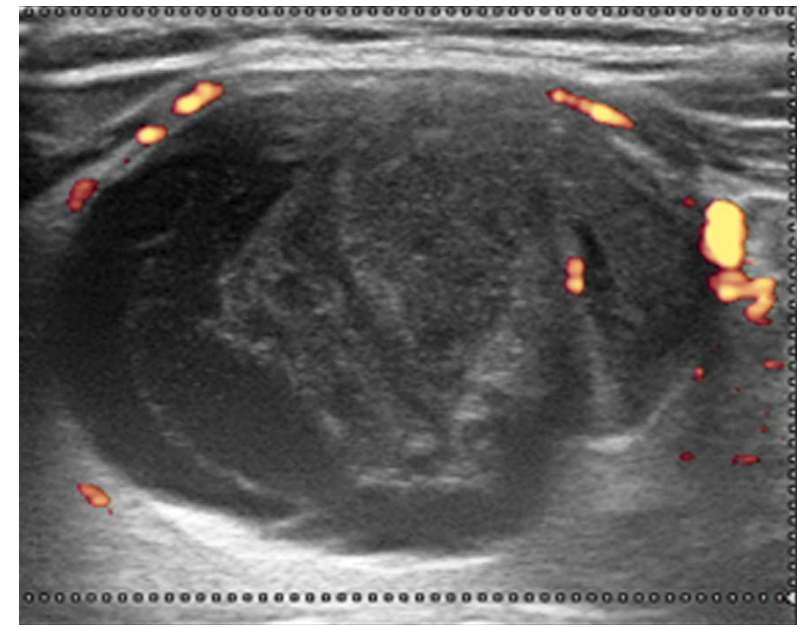

A

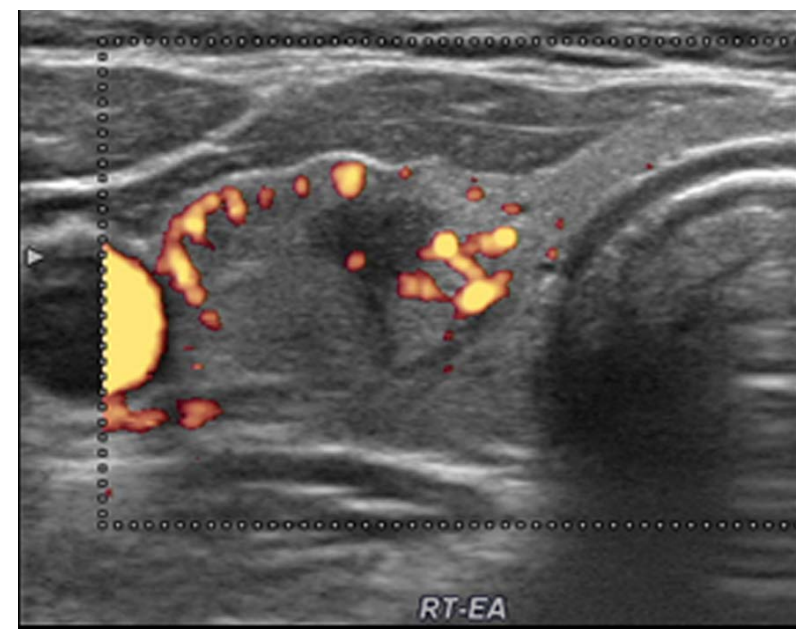

C

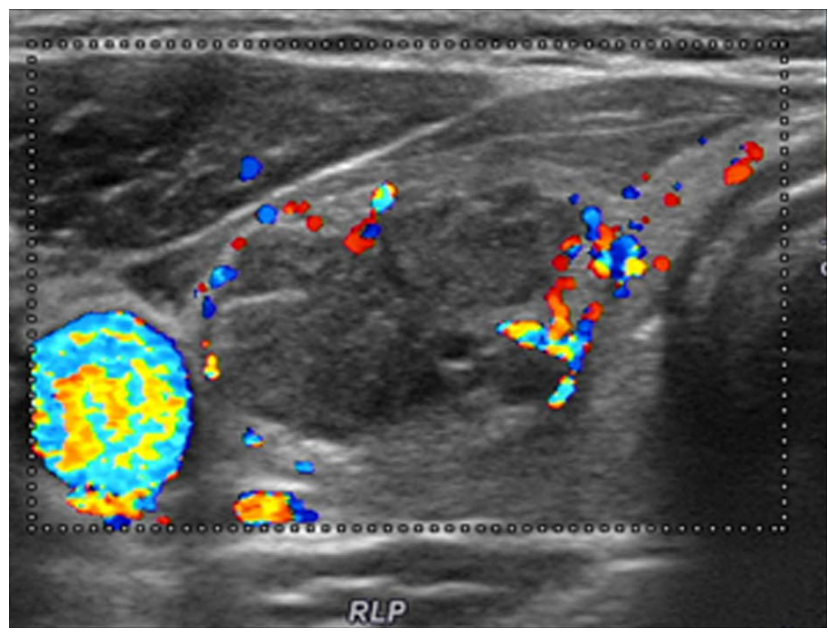

B

Fig. 4. A 63-year-old woman with predominantly cystic thyroid nodule. A. At the initial work-up, there was a cystic mass of about $10 \mathrm{~mL}$ with benign cytology on fine-needle aspiration in the right thyroid lobe. The initial cosmetic score was 4 , and the symptom score was 6 . The patient underwent ethanol ablation with $5 \mathrm{~mL}$ of ethanol, followed by the aspiration of $10 \mathrm{~mL}$ of cystic contents. B. At a 1-month follow-up, the size of the nodule had significantly decreased $(2.6 \mathrm{~mL}, 75.2 \%$ volume reduction ratio), but the nodule showed a solid component with vascularity (vascular grade 3 ) that was not definitely seen in the initial examination. As her symptoms had dramatically reduced to a symptom score of 2 after ethanol ablation, the patient underwent observation without additional treatment. C. At the 32-month follow-up, immediate additional treatment was still not necessary, as there were no symptoms (volume, $1.3 \mathrm{~mL}$; volume reduction ratio, $87.6 \%$ ), even though there might be the possibility of recurrence during long-term follow-up because of the solid component with vascularity.
We tried to reach 16 patients (10.4\%) who were lost to outpatient clinic follow-up after 1 month by telephone. Six of them who had achieved therapeutic success at the 1-month follow-up could not be reached, so we categorized them as cases of therapeutic success. Among the 10 patients who answered the telephone survey, one patient underwent re-treatment at another hospital and others did not have recurrent symptoms. We categorized the patient who underwent re-treatment as a case of therapeutic failure, while the others were categorized as therapeutic success.

There were no major adverse events such as voice change, infection, esophageal injury, or tracheal injury after EA or RFA.

\section{Discussion}

Our study demonstrated that EA achieved significant volume reduction and improvement of clinical problems. Moreover, there were no major complications after EA. When we applied the three previously proposed criteria $[2,6,7,9]$ to our patient group, additional treatment was avoidable in $81 \%, 70 \%$, and $71 \%$ of patients according to the previously suggested criteria 1, 2, and 3, respectively. Therefore, the choice to perform additional treatment should be made carefully according to both patients' actual clinical problems and US features. Understanding of this concept will be useful for doctors who perform US-guided EA to help them minimize unnecessary additional procedures.

EA is well known as an effective treatment for cystic thyroid nodules [21]. However, important issues of concern are how to define recurrence and when to plan for further treatment. As previous studies have proposed different criteria for recurrence and additional treatment planning $[2,6,7,9]$, confusion may arise during follow-up in clinical practice. Previous articles recommended making decisions on additional re-treatment at a 1-month followup according to US features such as the existence of $>1 \mathrm{~mL}$ of cystic fluid [6], a volume reduction ratio $<50 \%[7,9]$, or the presence of 


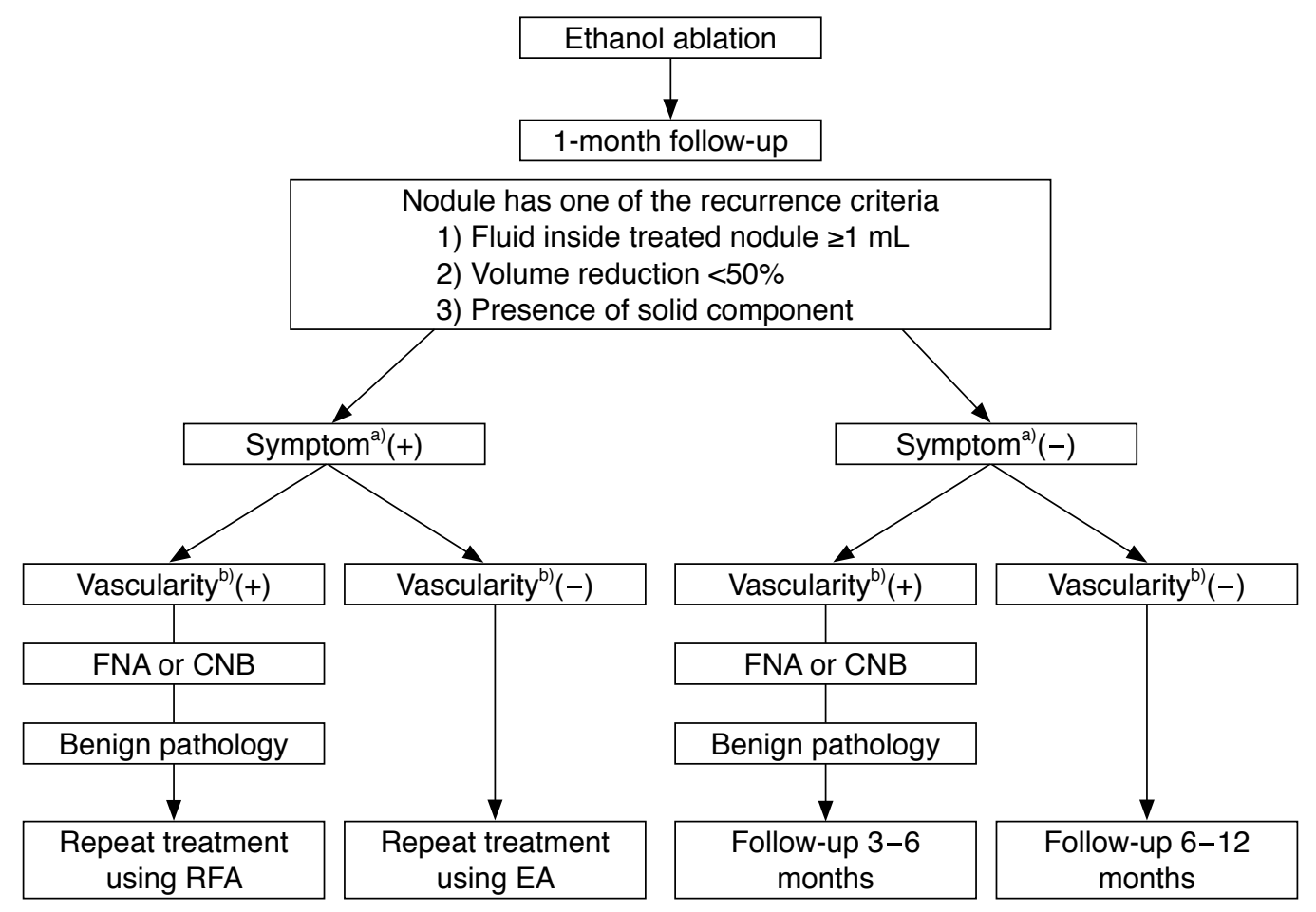

Fig. 5. Suggested additional treatment strategy after ethanol ablation (EA). FNA, fine-needle aspiration; CNB, core needle biopsy; RFA,

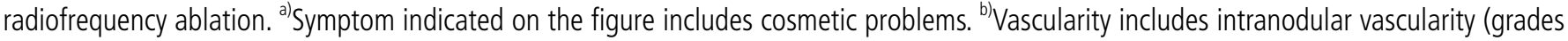
3 and 4).

a solid component with internal vascularity [2]. However, we found that simple observation without additional treatment could also achieve therapeutic success.

Previous studies reported that EA reduced the volume of cystic thyroid nodules by $85 \%-98.5 \%$ and the volume of predominantly cystic nodules by $64 \%-73.2 \%$ [13]. It has been suggested that the reason why cystic thyroid nodules typically show a greater volume reduction than benign solid nodules are that the solid components are more resistant to ethanol, and the vascular network of solid nodules drains the ethanol, thereby limiting the success of EA [22-24]. Furthermore, the solid component was found to be the only independent factor predicting volume reduction after a single session of EA [13]. In our study, we found that $84.2 \%$ of nodules (16 of 19) in the therapeutic failure group showed increased vascularity, which is in agreement with a previous report [2]. Vascularity is also an important factor contributing to therapeutic success after RFA or laser ablation [20,25-27]. Even though vascularity may be seen more prominently at a 1-month follow-up, the choice to perform additional treatment should be carefully made in asymptomatic patients [13,22].

Even though EA has been suggested as the first-line treatment for cystic or predominantly cystic nodules [14,28], repeated EA for recurrent cases has been reported to show markedly decreased treatment efficacy [6]. Thus, in cases of incompletely resolved initial clinical problems after EA, RFA has been introduced for additional treatment, rather than repeat EA $[13,22]$. Lee et al. [22] reported the results of additional RFA in 27 patients who had incompletely resolved clinical problems after EA. All 27 patients showed therapeutic success. In a prospective study [13], RFA achieved a $91 \%$ volume reduction in 22 of 94 patients who showed incompletely resolved symptoms.

Although therapeutic success was achieved at a 1-month follow-up, longer-term evaluation is necessary because of delayed recurrence. Suh et al. [2] reported that $24.1 \%$ (21 of 87 ) of patients exhibited delayed recurrence during an average follow-up of 10.1 months. Fourteen of 21 cases of delayed recurrence treated with RFA showed 100\% therapeutic success [2]. In our study, we experienced seven cases of delayed recurrence and performed RFA for additional treatment, which showed therapeutic success, with an average volume reduction ratio of $80.2 \%$.

This study has several limitations. First, the retrospective nature of this study and the fact that it included patients from a single center means that it may have been affected by selection bias. Second, the included population was relatively small, which could have reduced the sensitivity of the study results. Third, follow-up was undertaken using a telephone survey for 16 patients who did not make further 
follow-up visits after the first follow-up at 1 month after EA. We evaluated whether the patients had new symptoms or enlargement of nodules, and if they did not complain of any symptoms, their case was considered a therapeutic success. Thus, we could not evaluate the final US findings for these patients, and assumed that EA achieved its treatment goal as long as the 1-month follow-up US did not show any suspicious features for recurrence and the patients did not return to the clinic complaining of any symptoms. Lastly, there is still potential for delayed recurrence in the future.

We propose an additional management algorithm for thyroid nodules treated by EA, as depicted in Fig. 5. We recommend that physicians who perform EA for cystic nodules consider further alternatives such as observation or repeated pathologic confirmation when choosing between treatment options based on patients' clinical situation.

The decision of whether to perform additional treatment after EA for cystic or predominantly cystic thyroid nodules should be carefully made using a combination of patients' actual clinical problems and US features. Understanding this concept will be useful for doctors who perform US-guided EA, and will assist them in planning for additional procedures.

ORCID: Younghee Yim: https://orcid.org/0000-0002-4224-7832; Jung Hwan Baek: https://orcid.org/0000-0003-0480-4754; Sae Rom Chung: https://orcid.org/00000003-4219-7166; Young Jun Choi: https://orcid.org/0000-0001-7098-5042; Jeong Hyun Lee: https://orcid.org/0000-0002-0021-4477

\section{Author Contributions}

Conceptualization: Yim Y, Baek JH, Chung SR, Choi YJ, Lee JH. Data acquisition: Yim Y, Baek JH, Lee JH. Data analysis or interpretation: Yim Y, Baek JH. Drafting of the manuscript: Yim Y, Chung SR, Choi YJ, Lee JH. Critical revision of the manuscript: Baek JH. Approval of the final version of the manuscript: all authors.

\section{Conflicts of Interest}

No potential conflict of interest relevant to this article was reported.

\section{References}

1. Hahn SY, Shin JH, Na DG, Ha EJ, Ahn HS, Lim HK, et al. Ethanol ablation of the thyroid nodules: 2018 consensus statement by the Korean Society of Thyroid Radiology. Korean J Radiol 2019;20:609620.

2. Suh CH, Baek JH, Ha EJ, Choi YJ, Lee JH, Kim JK, et al. Ethanol ablation of predominantly cystic thyroid nodules: evaluation of recurrence rate and factors related to recurrence. Clin Radiol 2015;70:42-47.
3. Kim JH, Baek JH, Lim HK, Na DG. Summary of the 2017 thyroid radiofrequency ablation guideline and comparison with the 2012 guideline. Ultrasonography 2019;38:125-134.

4. Bennedbaek FN, Karstrup S, Hegedus L. Percutaneous ethanol injection therapy in the treatment of thyroid and parathyroid diseases. Eur J Endocrinol 1997;136:240-250.

5. Monzani F, Lippi F, Goletti O, Del Guerra P, Caraccio N, Lippolis PV, et al. Percutaneous aspiration and ethanol sclerotherapy for thyroid cysts. J Clin Endocrinol Metab 1994;78:800-802.

6. Bennedbaek FN, Hegedus L. Treatment of recurrent thyroid cysts with ethanol: a randomized double-blind controlled trial. J Clin Endocrinol Metab 2003;88:5773-5777.

7. Del Prete $S$, Caraglia M, Russo D, Vitale G, Giuberti G, Marra M, et al. Percutaneous ethanol injection efficacy in the treatment of large symptomatic thyroid cystic nodules: ten-year follow-up of a large series. Thyroid 2002;12:815-821.

8. Kim DW, Rho MH, Kim HJ, Kwon JS, Sung YS, Lee SW. Percutaneous ethanol injection for benign cystic thyroid nodules: is aspiration of ethanol-mixed fluid advantageous? AJNR Am J Neuroradiol 2005;26:2122-2127.

9. Zingrillo M, Torlontano M, Chiarella R, Ghiggi MR, Nirchio V, Bisceglia $M$, et al. Percutaneous ethanol injection may be a definitive treatment for symptomatic thyroid cystic nodules not treatable by surgery: five-year follow-up study. Thyroid 1999;9:763767.

10. Shin JH, Baek JH, Chung J, Ha EJ, Kim JH, Lee YH, et al. Ultrasonography diagnosis and imaging-based management of thyroid nodules: revised Korean Society of Thyroid Radiology Consensus Statement and Recommendations. Korean J Radiol 2016;17:370-395.

11. Jeong WK, Baek JH, Rhim H, Kim YS, Kwak MS, Jeong HJ, et al. Radiofrequency ablation of benign thyroid nodules: safety and imaging follow-up in 236 patients. Eur Radiol 2008;18:1244-1250.

12. Kim YJ, Baek JH, Ha EJ, Lim HK, Lee JH, Sung JY, et al. Cystic versus predominantly cystic thyroid nodules: efficacy of ethanol ablation and analysis of related factors. Eur Radiol 2012;22:1573-1578.

13. Jang SW, Baek JH, Kim JK, Sung JY, Choi H, Lim HK, et al. How to manage the patients with unsatisfactory results after ethanol ablation for thyroid nodules: role of radiofrequency ablation. Eur J Radiol 2012;81:905-910.

14. Baek JH, Kim YS, Lee D, Huh JY, Lee JH. Benign predominantly solid thyroid nodules: prospective study of efficacy of sonographically guided radiofrequency ablation versus control condition. AJR Am J Roentgenol 2010;194:1137-1142.

15. Na DG, Lee JH, Jung SL, Kim JH, Sung JY, Shin JH, et al. Radiofrequency ablation of benign thyroid nodules and recurrent thyroid cancers: consensus statement and recommendations. Korean J Radiol 2012;13:117-125.

16. Sung JY, Baek JH, Kim YS, Jeong HJ, Kwak MS, Lee D, et al. One- 
step ethanol ablation of viscous cystic thyroid nodules. AJR Am J Roentgenol 2008;191:1730-1733.

17. Sung JY, Kim YS, Choi H, Lee JH, Baek JH. Optimum first-line treatment technique for benign cystic thyroid nodules: ethanol ablation or radiofrequency ablation? AJR Am J Roentgenol 2011;196:W210-W214.

18. Shin JE, Baek JH, Lee JH. Radiofrequency and ethanol ablation for the treatment of recurrent thyroid cancers: current status and challenges. Curr Opin Oncol 2013;25:14-19.

19. Park HS, Yim Y, Baek JH, Choi YJ, Shong YK, Lee JH. Ethanol ablation as a treatment strategy for benign cystic thyroid nodules: a comparison of the ethanol retention and aspiration techniques. Ultrasonography 2019;38:166-171.

20. Jung SL, Baek JH, Lee JH, Shong YK, Sung JY, Kim KS, et al. Efficacy and safety of radiofrequency ablation for benign thyroid nodules: a prospective multicenter study. Korean J Radiol 2018;19:167-174.

21. Lang BH, WU ALH. The efficacy and safety of high-intensity focused ultrasound ablation of benign thyroid nodules. Ultrasonography 2018;37:89-97.

22. Lee JH, Kim YS, Lee D, Choi H, Yoo H, Baek JH. Radiofrequency ablation (RFA) of benign thyroid nodules in patients with incompletely resolved clinical problems after ethanol ablation (EA).
World J Surg 2010;34:1488-1493.

23. Weisskoff RM, Boxerman JL, Sorensen AG, Kulke SM, Campbell TA, Rosen BR. Simultaneous blood volume and permeability mapping using a single Gd-based contrast injection. In: Proceedings of the Society of Magnetic Resonance, Second Annual Meeting; 1994 Aug 6-12; San Francisco, CA, USA.

24. Park HS, Baek JH, Choi YJ, Lee JH. Innovative techniques for imageguided ablation of benign thyroid nodules: combined ethanol and radiofrequency ablation. Korean J Radiol 2017;18:461-469.

25. Baek JH. Factors related to the efficacy of radiofrequency ablation for benign thyroid nodules. Ultrasonography 2017;36:385-386.

26. Oddo S, Felix E, Mussap M, Giusti M. Quality of life in patients treated with percutaneous laser ablation for non-functioning benign thyroid nodules: a prospective single-center study. Korean J Radiol 2018;19:175-184.

27. Pacella CM, Mauri G, Cesareo R, Paqualini V, Cianni R, De Feo P, et al. A comparison of laser with radiofrequency ablation for the treatment of benign thyroid nodules: a propensity score matching analysis. Int J Hyperthermia 2017;33:911-919.

28. Lee SJ, Ahn IM. Effectiveness of percutaneous ethanol injection therapy in benign nodular and cystic thyroid diseases: long-term follow-up experience. Endocr J 2005;52:455-462. 